Original Research Article

\title{
A study of knowledge and practice for disposal of unused and expired pharmaceuticals among medical undergraduates at tertiary care teaching hospitals in Uttar Pradesh, India
}

\author{
Meenakshi Jindal' ${ }^{1}$, Raj Kumar Goel ${ }^{2 *}$
}

\begin{abstract}
${ }^{1}$ Department of Pharmacology, Muzaffarnagar Medical College, Muzaffarnagar, Uttar Pradesh, India

${ }^{2}$ Department of Pharmacology, LLRM Medical College, Meerut, Uttar Pradesh, India
\end{abstract}

Received: 12 September 2018 Accepted: 22 October 2018

*Correspondence to:

Dr. Raj Kumar Goel,

Email:drrajgoel@yahoo.com

Copyright: () the author(s), publisher and licensee Medip Academy. This is an openaccess article distributed under the terms of the Creative Commons Attribution NonCommercial License, which permits unrestricted noncommercial use, distribution, and reproduction in any medium, provided the original work is properly cited.

\begin{abstract}
Background: Increasing disease incidence and prevalence necessitate healthcare practitioners to prescribe diverse medications. Families and patients are in possession of unused or expired medications and its risks have started gaining notice across the world. Majority of them including medical students are unaware about the disposal of unused or expired medicines. Misuse and improper disposal of unused/expired medications is a major safety and environmental concern, and thus proper disposal of those medications is highly important.

Methods: Questionnaire based study was conducted among medical undergraduates of third year MBBS in two tertiary care teaching hospitals of Uttar Pradesh after approval from Institutional Ethical Committees during JulyAugust 2018.

Results: There were $65 \%$ of respondent had unused drugs in their home while $30 \%$ had the expired drugs. The most common reason for the unused and expiry drugs in the home was self-discontinuation. Analgesics were the main group of drugs possessed by participants. $67 \%$ in this study responded that drug disposal method was disposing the expired drugs to garbage. Only $26 \%$ know about the area in the city where unused/expired drugs are collected. $46 \%$ think that proper education of the community is required for appropriate disposal of unused drugs. Conclusions: Intervention by education about prudent drug disposal techniques that are also environmentally safe and acceptable is the need of time to change their behavior. There is also needing to understand the practice and awareness of the public to make any such education by program a success.
\end{abstract}

Keywords: Analgesic, Drug disposal, Expired drugs, Unused drugs, Yellow bags

\section{INTRODUCTION}

Increasing disease incidence and prevalence necessitate healthcare practitioners to prescribe and dispense different medications. The patients are not able to use all the dispensed medications because of adverse effects, alteration of dosage, feeling healthy, medications reaching the expiration date, promotional practices by manufacturers', physicians' prescribing practices, or dispensers' practices. ${ }^{1,2}$ According to World Health Organization (WHO), more than half of all medication is inappropriately prescribed, prescribed and sold, which causes unnecessary storage and creates environmental threat. ${ }^{3}$ Non-adherence to medication can also cause storage of left over medicines at home. According to WHO $50 \%$ of patients fail to take medicine correctly. ${ }^{4}$ Therefore, it is usual that, families and patients are in possession of unused or expired medications and its risks have gained attention across the world. ${ }^{5}$

With the increased use of medicines both in human and veterinary practice, the extent of environmental contamination is also high. ${ }^{6}$ The potential routes of entry of medications into the environment are through patient 
excretion into the sewage system, direct release through sewage from manufacturing units, or disposal of unused medication via trash or flushing. ${ }^{7}$ Few outcomes of such environmental contamination are a decline in number of vultures, sterility in frogs, and feminization of male fishes. ${ }^{8,9}$

In addition, inappropriate disposal of unwanted medicines including out-of-date medicines may further contaminate the environment. ${ }^{10}$ The excretion of synthetic gestagens, levonorgestrel and drospirenone, from the body into water bodies has adversely caused masculinization of female fishes and inhibition of their reproduction. ${ }^{11}$ Accumulation of unused and expired medicines at households usually results from excessive prescribing by doctors and/or poor patients' adherence to prescribed medicines. ${ }^{12,13}$

This is a serious threat worldwide and has opened a new branch of science called Ecopharmacovigilance (EPV). EPV is concerned with detection, assessment, understanding, and prevention of adverse effects related to the presence of pharmaceuticals in the environment, which affect human and other animal species. ${ }^{14}$ The approaches of EPV include green drug design, green chemistry in process development, development of biodegradable products, minimization of manufacturing emissions, education over rational use of drugs, improved prescribing practices, and safe disposal of unused drugs. ${ }^{15,16}$

If unused postexpiry date medicines are disposed inappropriately, they may further increase the threat to the environment as such medicines may have different safety profile. For example, expired tetracyclines can cause renal tubular damage. ${ }^{17}$ The impact of improper disposal of expired medicines has not been studied in the literature. To minimize the adverse impact of pharmaceutical compounds on the environment, the challenges related to the improper disposal of unused and expired medicines needs to be addressed. ${ }^{12,13}$

For instance, non-steroidal anti-inflammatory drug (NSAID) diclofenac has been shown to induce renal failure in vultures following the ingestion of carrion from cattle treated with this drug. ${ }^{18}$ Evidence shows that the presence of antibiotics in water may lead to antibiotic resistance and in long term may cause genetic effects in humans and marine life. ${ }^{19,20}$

Medication disposal habits are influenced by environmental awareness, availability of guidelines, dosage form, and social and cultural attitudes. The most environmental unfriendly means of drug disposition are disposing drugs into the sink, toilet, or into the dust bin. In India, the major reason for possession of unused, expired medicines is reported to be due to purchase of over the counter (OTC) drugs for self-medication. ${ }^{21}$

In addition to the availability of required infrastructure (e.g., landfill, incinerator) to dispose of unwanted and expired medicines, it is imperative that the public, including healthcare professionals (HCPs), are aware of proper disposal methods and harms associated with their improper disposal. A survey conducted in the UK revealed unhealthy practices of 400 households where they disposed unused and expired pharmaceuticals either as household waste or via the sink or toilet. ${ }^{22}$ An Indian study on the knowledge, attitude, and beliefs of dental students about the disposal methods for expired and leftover medicines recommended the need to improve their awareness about safe and prudent disposal methods. ${ }^{23}$

Therefore, WHO's European Centre for Environment and Health in France, set up an international working group to produce a practical guide, addressing particularly the problems of HCWM in developing economies. ${ }^{24}$ In addition, some programs such as Disposal of Unwanted Medication Properly (DUMP) campaign was launched in New Zealand and in Canada ENVIRx disposal program was initiated. ${ }^{25,26}$ With this background, the present study was conducted to assess the Knowledge of Practice for disposal of unused and expired pharmaceuticals among medical undergraduates.

\section{METHODS}

The study was conducted in two tertiary care teaching hospitals of western Uttar Pradesh after approval from Institutional Ethical Committees. It was a descriptive cross sectional, questionnaire based study conducted among medical undergraduates. The study was conducted in the month of July-August 2018. Informed consent was taken from the students prior to the study.

The questionnaire containing thirteen items was distributed among students and time of 20 minutes was given to each student for filling the form. The questionnaire consisted of questions regarding having unused drug or expired drug, the type of unused/expired medications at home and their numbers, reasons for stockpiling of leftover drugs, dosage forms, disposal techniques and methods adopted by the students to dispose expired medications and questions exploring their knowledge like they know the exact method of disposal of unused / expired drug, if yes then from where did they got such knowledge like books, internet etc. and to assess the practice about safe drug disposal methods. The students were asked about yellow bags where expired drugs are collected. They were also asked about "Aushadhi Bank" placed in hospital attached to LLRM Medical College Meerut for collection of unused drugs that can be used for other patients, drop box, NGO who collect the unused drug. They were asked to enumerate the drugs that were usually left unused. The students were asked about the awareness regarding the effect of pharmaceuticals on environment. They were also asked about steps to be taken to educate people about drug disposal and best place to educate them.

Medical undergraduates of second year and third year MBBS were included in the study while first year, final 
year undergraduates, the students who were unwilling to fill the questionnaire, junior residents and senior residents were excluded from the study. The data from the two hospitals was collected on the Microsoft excel sheets. The data was analyzed and results are expressed in counts and percentages.

\section{RESULTS}

Total of 426 questionnaires were distributed among medical undergraduates of second and third year MBBS, aged between 20-25 years. Out of those 406 completely filled questionnaire were returned back. 20 respondents were excluded from the study because of incompletely filling. $58 \%$ of the participants were males and $42 \%$ females. $65 \%$ of respondent had unused drugs in their home, $30 \%$ had the expired drugs and $5 \%$ had both the types of the drugs. $67 \%$ of them have $2-5$ drugs, $24 \%$ have 5-9 drugs while $9 \%$ have more than 10 drugs with them.

The most common reason for the unused and expiry drugs in the home was self discontinuation in $75 \%$ which was mainly due to improvement in disease and some even declared they had to discontinue the treatment because of adverse effect like gastritis and nausea while $25 \%$ have gave multiple reasons in addition like doctor prescribed more than needed or doctor changed the treatment due to other reason.

Class of unused / expired drugs at home were mainly analgesics (34\%) and antibiotics (29\%) while few of them had antipyretics $(11 \%)$, cough syrups $(10 \%)$, topical formulations (8\%) and anti-histaminic (8\%) (Figure 1).

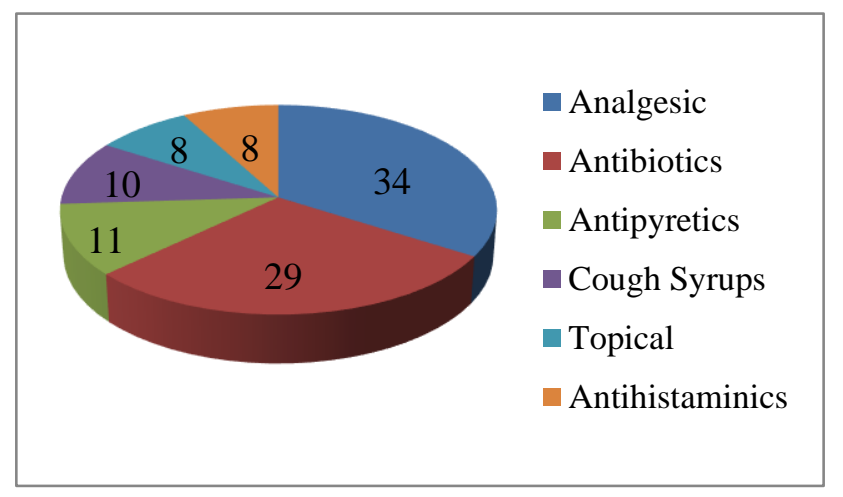

Figure 1: Class of unused/ expired drugs.

There were $82 \%$ of them have solid dosage form while rests have liquid, inhalation and topical forms. 55\% of them knew about proper disposal while $45 \%$ did not have knowledge about that. Of those having knowledge about proper disposal $40 \%$ knew about yellow bags in hospital for disposal of expired drugs. 77\% disposed expired drug by throwing them in garbage or rinsing down the sink and flushing in toilet. $23 \%$ respondent agreed that they returned unused drug to the pharmacists.
There were $74 \%$ of them do not know the area of city where unused drugs were collected. Only $3 \%$ had the correct knowledge about giving to collection center at NGO or drop them in DROP BOXES in the hospitals, $60 \%$ showed their concern that improper disposal can affect the environment and health while $40 \%$ does not know about hazardous effects of unused/expired drugs. In a Response to a question regarding steps to be taken for proper disposal of unused/ expired drugs; $46 \%$ answered for proper education, $20 \%$ for awareness and $19 \%$ suggested for rallies and plays. $13 \%$ of them concern for media through electronic, newspaper (Table 1).

Table 1: Modes of intervention for proper disposal of unused/expired drugs.

\begin{tabular}{|lll|}
\hline S. no. & $\begin{array}{l}\text { Mode of } \\
\text { intervention }\end{array}$ & Percentage (number) \\
\hline 1 & Education & $46(n=188)$ \\
\hline 2 & Awareness & $20(n=82)$ \\
\hline 3 & Rally and Play & $19(n=76)$ \\
\hline 4 & Media & $15(n=60)$ \\
\hline
\end{tabular}

\section{DISCUSSION}

Majority of students in this study had unused drugs at their home which is very high than findings of Sirisha et al study where $67 \%$ had upto 5 leftover drugs in tablet form in majority of cases while $46.88 \%$ had unused drug in study by Shivaraju et al. ${ }^{27,28}$

Among the reason for possession of unused drugs, self discontinuation was $75 \%$ in this study which is comparable to studies by Maharana et al, Sirisha et al, and OseiDjarbeng. ${ }^{27,29,30}$ Our results were far higher than study by Ahmed et al. ${ }^{31}$ Other reasons like left over from previous OTC, doctor changed the medicines and drug passed expiry date were also there which are at par with other studies. $^{27,29}$

Most of the unused drugs kept at home belongs to analgesics (34\%) and antibiotics (29\%) while few of them had antipyretics $(11 \%)$, cough syrups (10\%), topical formulations $(8 \%)$ and anti-histaminic $(8 \%)$. Our results are comparable to study by Ahmed et al, where NSAIDs use was highest as $30 \% .{ }^{31}$ In a study by Shivaraju et al, commonly stored drugs were topical, analgesics and antipyretics while in a study by Maharana et al, most commonly antacids were stored. ${ }^{28,29} 82 \%$ participants have solid dosage forms while rest $18 \%$ include liquid, inhalation and topical forms and this is similar to study by Shivaraju et al, but differs from Sirisha et al, study where syrups and capsules were stored commonly. ${ }^{27,28} 23 \%$ participants were in favor of returning unused drugs to pharmacist which is very less than the study by Swaroop et al, in which it was $62 \% .{ }^{32}$ It is a good practice which should be done promptly. Earlier studies emphasized to implement take back programs in India. $67 \%$ in this study responded that acceptable drug disposal method adopted was disposing to garbage at their home; this is similar to 
studies. $^{27,32,33} 17 \%$ of them were in favor of rinsing down the sink and flushing in toilet which is very less than study by Swaroop et al, where $83 \%$ empties liquid medicaments in the sink and gives glass bottle for recycle use. ${ }^{32}$

In the process of drug development, a new chemical entity is not studied for any deterioration in its efficacy, potency, and safety after proposed expiry date; however, its expiry date is based on stability and sterility studies. It is documented that at expiry, drugs should be at least $90 \%$ potent. ${ }^{34} 60 \%$ respondent showed their concern for the environment by the improper disposal while it was $74.22 \%$ in a study by Shivaraju et al, and $28 \%$ by Swaroop et al. ${ }^{28,32}$

In this study, it is quite clear that the Knowledge and practice of drug disposal among the medical undergraduate is inappropriate. Intervention by education about prudent drug disposal techniques that are also environmentally safe and acceptable will help change their behavior. A proactive approach such as incorporating this important issue in their curriculum is the need of the hour. There is also a pressing need to establish cost-effective and acceptable state-run collection and disposal systems. Conscientious and proper disposal of medications can help to decrease environmental load of drugs. There is also need to understand the practice and awareness of the public to make any such program a success.

Funding: No funding sources

Conflict of interest: None declared

Ethical approval: The study was approved by the Institutional Ethics Committee

\section{REFERENCES}

1. Seehusen DA, Edwards J. Patient practices and beliefs concerning disposal of medications. J Am Board Fam Med. 2006;19(6):542-7.

2. Ruhoy IS, Daughton CG. Beyond the medicine cabinet: an analysis of where and why medications accumulate. Environ Int. 2008;34(8):1157-69.

3. WHO. Challenges in expanding access to essential medicines; 2004. 2014. Available at: http://apps.who.int/medicinedocs/en/d/Js5571e/2.htm 1. Accessed 30 June 2016.

4. WHO. The world medicines situation. 2004. Available at: http://apps.who.int/ medicinedocs/pdf/s6160e/s6160e.pdf Accessed 30 June 2016.

5. Ananth AP, Prashanthini V, Visvanathan C. Healthcare waste management in Asia. Waste Manag. 2010;30(1):154-61.

6. Wang J, Hu X. Ecopharmacovigilance: Current state, challenges, and opportunities in China. Indian J Pharmacol. 2014;46:13-7.

7. Srivastava B, Sinha AK, Gaur S, Gaur S, Palaria U. Ecopharmacovigilance: Its importance and challenges. J Biomed and Pharmaceutical Res. 2014;3:81-7.
8. Oaks JL, Gilbert M, Virani MZ, Watson RT, Meteyer CU, Rideout BA, et al. Diclofenac residues as the cause of vulture population decline in Pakistan. Nature. 2004;427:630-3.

9. Kvarnryda M, Grabicb R, Brandta I, Berg C. Early life progestin exposure causes arrested oocyte development, oviductal agenesis and sterility in adult Xenopus tropicalis frogs. Aquat Toxicol. 2011;103:18-24.

10. Comeau F, Surette C, Brun GL, Losier R. The occurrence of acidic drugs and caffeine in sewage effluents and receiving waters from three coastal watersheds in Atlantic Canada. Sci Total Environ. 2008;396:132-46.

11. Zeilinger J, Steger-Hartmann T, Maser E, Goller S, Vonk R, Länge R. Effects of synthetic gestagens on fish reproduction. Environ Toxicol Chem. 2009;28:2663-70.

12. Ekedahl AB. Reasons why medicines are returned to Swedish pharmacies unused. Pharm World Sci. 2006;28:352-8.

13. Lindberg MJ, Andersen SE, Christensen HR, Kampmann JP. Compliance to drug prescriptions. Ugeskr Laeger. 2008;170:1912-6.

14. Medhi B and Sewal RK. Ecopharmacovigilance: An issue urgently to be addressed. Indian J Pharmacol. 2012; 44(5): 547-549.

15. BIO Intelligence Service. Study on the environmental risks of medicinal products, Final Report prepared for Executive Agency for Health and Consumers; 2013. Available ec.europa.eu/health/files/environment/study_environ ment.pdf, accessed on Oct 12, 2014.

16. Velo G, Moretti U. Ecopharmacovigilance for better health. Drug Saf. 2010;33:963- 8.

17. Frimpter GW, Timpanelli AE, Eisenmenger WJ, Stein HS, Ehrlich LI. Reversible Faconi syndrome caused by degraded tetracycline. JAMA. 1963;184:111-3.

18. Oaks JL, Gilbert M, Virani MZ, Watson RT, Meteyer $\mathrm{CU}$, Rideout BA, et al. Diclofenac residues as the cause of vulture population decline in Pakistan. Nature. 2004;427(6975):630-3.

19. Costanzo SD, Murby J, Bates J. Ecosystem response to antibiotics entering the aquatic environment. Mar Pollut Bull. 2005;51(1):218-23.

20. Wu M, Atchley D, Greer L, Janssen S, Rosenberg D, Sass J. Dosed without prescription: preventing pharmaceutical contamination of our nation's drinking water. Natural Resources Defense Council White Pape;. 2009:1-60.

21. Holm G, Snape JR, Murray-Smith R, Talbot J, Taylor $\mathrm{D}$, Sorme P. Implementing ecopharmacovigilance in practice: Challenges and potential opportunities. Drug Saf. 2013;36:533-46.

22. Bound JP, Voulvoulis N. Household disposal of pharmaceuticals as a pathway for aquatic contamination in the United Kingdom. Environ Health Perspect. 2005;113:1705-11. 
23. Aditya S. Safe medication disposal: Need to sensitize undergraduate students. Int $\mathbf{J}$ Pharm Life Sci. 2013;4:2475-80.

24. Prüss A, Giroult E, Rushbrook P. Safe management of wastes from healthcare activities: World Health Organization; 1999.

25. Braund R, Peake BM, Shieffelbien L. Disposal practices for unused medications in New Zealand. Environ Int. 2009;35(6):952-5.

26. Gagnon E. Pharmaceutical disposal programs for the public: A Canadian perspective. Ottawa, Ontario: Health Canada, Environmental Impact Initiative; 2009.

27. Sirisha A, Janardhan M, Sree PK, Rao YV, Raikar SR, Patil S, et al. Knowledge, attitude and practice on safe disposal of medicines among medical and dental undergraduates. J Basic Clin Res. 2016;3(1):5-9.

28. Shivaraju PT, Gangadhar M. Knowledge and awareness of disposal of unused and expired medications among medical undergraduates of $\mathrm{A}$ Tertiary Care Teaching Hospital at B G Nagar: A cross-sectional observational study. Natl J Physiol Pharm Pharmacol. 2017;7(11):1268-73.

29. Maharana SP, Paul B, Dasgupta A, Garg S. Storage, reuse, and disposal of unused medications: A crosssectional study among rural households of Singur, West Bengal. Int $\mathbf{J}$ Med Sci Public Health. 2017;6(7):1185-9.

30. Osei-Djarbeng SN, Larbi GO, Abdul-Rahman R, Osei-Asante S, Owusu-Antwi R. Household acquisition of medicines and disposal of expired and unused medicines at two suburbs (Bohyen and Kaase) in Kumasi-Ghana. Pharm Innov J. 2015;4(8):85-8.

31. Ahmed A, Mushtaq N, Tariq M, Durrani M, Akhtar S, Arif M, et al. Disposal practices of unused and expired pharmaceuticals in Karachi and their impact on health and environment. JUMDC. 2013;2007(4):2.

32. Swaroop HS, Chakraborty A, Virupakshaiah A. Knowledge, attitude and practice of medical professionals towards the safe disposal of unused medications in south India. World J Pharm Pharm Sci. 2015;4(5):1423-30.

33. Lagishetty R, Nagarajan P, Vijayanandhan SS. Practice towards disposal of medicines (left out/expired drugs) among the patients visiting tertiary care teaching hospital and primary health centre in south India. Asian J Biochem Pharm Res. 2013;1(4):175-82.

34. Expired Medications. Available at: http://www.emedexpert. com/tips/expired-meds. html. [Last accessed 2015 Nov 25; Last updated on 2105 Dec 24].

Cite this article as: Jindal M, Goel RK. A study of knowledge and practice for disposal of unused and expired pharmaceuticals among medical undergraduates at tertiary care teaching hospitals in Uttar Pradesh, India. Int J Basic Clin Pharmacol 2018;7:2447-51 